\title{
Occupational epidemiologist's quest to tame measurement error in exposure
}

\author{
Igor Burstyn \\ Department of Environmental and Occupational Health \\ Department of Epidemiology and Biostatistics \\ Dornsife School of Public Health \\ Drexel University \\ Nesbitt Hall \\ Room 614 \\ 3215 Market Street \\ Philadelphia, PA 19104 \\ USA \\ E-mail: igor.burstyn@drexel.edu
}

Keywords: exposure measurement error; observational error; exposure misclassification; bias in epidemiology; occupational epidemiology; bias correction

\begin{abstract}
I aimed to assess current practices and opportunities for addressing the problem of errors in exposure in occupational epidemiology. Occupational epidemiologists appreciate that errors in exposure are a concern, but almost none correct for these errors, although there are currently no theoretical and practical barriers for this inertia. The most serious barrier to change is a faulty belief that a well-conducted epidemiologic study suffers only non-differential exposure misclassification and that its sole impact is to attenuate risk gradients, causing a false negative. On the contrary, differential exposure misclassification is the most defensible model in occupational epidemiology, and errors in exposure increase chance of both false positive and negative results. Resistance to mathematical adjustment (correction) for errors in exposure is equivalent to denying the value of more valid exposure estimates and undermines the discipline's relevance to protection of workers by informing workplace exposure limits.
\end{abstract}




\section{Introduction}

The following review is colored by my experiences in studying measurement error problem in context of occupational epidemiology and hygiene. It is likely that others travelled on paths, divergent or parallel, that led to their current understanding of this issue, but presentation of one such paths among many possible will aid scholars now entering the field and may help veterans reflect on their own journey to date. It should also embolden persons with minimal formal training in statistics not to shy away from cutting-edge statistical tools.

Before we proceed further, I will clarify that by "measurement error" I will mean difference between true and observed continuous exposure and by "misclassification" I will mean error in classifying binary state of exposure. The simplest forms of measurement error are described by classical and Berkson models. In classical measurement error model,

$\mathrm{W}=\mathrm{X}+\varepsilon$,

where $\mathrm{W}$ is observed exposure, $\mathrm{X}$ is true exposure, and $\varepsilon$ is zero-mean and independent of $\mathrm{X}$.

In Berkson measurement error model,

$\mathrm{X}=\mathrm{W}+\varepsilon$, where $\varepsilon$ is zero-mean and independent of $\mathrm{W}$.

The simplest form of exposure misclassification is described by sensitivity $(\operatorname{Pr}[\mathrm{W}=1 \mid \mathrm{X}=1])$ and specificity $(\operatorname{Pr}[\mathrm{W}=0 \mid \mathrm{X}=0])$. I purposefully do not specify what $\mathrm{X}$ is: be it (a) either peak exposure, or cumulative exposure lagged by 20 years in measurement error models, or (b) either ever versus never exposed, or highly exposed for $>20$ years versus exposed to low level for $>20$ years in misclassification model. These error models can be either non-differential or differential with respect to outcome; the error terms can be either independent of errors in outcomes and other exposures, or correlated with them.

\section{Recent history}

I will hazard a guess that many of my contemporaries (occupational health researchers), after becoming aware of importance of errors in exposure to valid inference in epidemiology, as part of their graduate training, pursued a more in-depth exploration of the topic either through work of Preller et al.[1] or Armstrong.[2] Preller et al.[1] is regularly cited over the years in 62 publications, overwhelmingly in occupational health literature, according to Web of Science. Armstrong [2] has now been cited 288 times, primarily in occupational journals, according to Web of Science. The citation patterns declined in time, and yet reflects the need in the field to invoke arguments about impact of error in exposure and means to mitigate it.

As the matters stood in the fading decade of the $20^{\text {th }}$ century, there were no accessible text on the subject that targeted occupational epidemiologists, although at least one superb monograph, first produced in 1992 by White et al.[3], aimed at epidemiologists in general, was available. It is still a mandatory reading for any serious student of exposure assessment with interest in measurement error. The matters changed by early 2000's with advent of more in-depth texts on the subject by statisticians that were accessible to epidemiologists, such as book by Prof. Gustafson [4] and series by Prof. Carroll et al.,[5, 6] reflecting more fundamental developments in statistics compiled by Prof. Fuller.[7] For those seeking introduction to practicalities of Bayesian approach to misclassification of exposure, Luta et al.[8] now offer accessible guidance. Treatment of measurement error and misclassification in individually matched case-referent studies used to present a problem that has now been largely surmounted using Bayesian [9, 10] and probabilistic [11] approaches. Exposure misclassification that arises from some approaches particular to occupational epidemiology recently receive theoretical analysis that placed them on solid theoretical footing, including multi-category exposures (e.g. none, low, medium, high)[12] and when true binary exposure (e.g. ever exceeded exposure limit for a given compound: yes/no?) is assessed as ordinal categories of increase chance of being present (e.g. unlikely, maybe, and likely exposed).[13] 
Probabilistic uncertainty analysis for dealing with errors in exposure (in conjunction with other systematic errors) is increasable featured in occupational epidemiology;[14] and accessible methodological guidance exists on its implementation.[15, 16]

Curiously, at around the time when subtleties of measurement error problem were becoming better illuminated, there was an effort by Blair et al.[17] to dismiss the problem altogether as unimportant relative to everything else that epidemiologists worry about, like confounding. I feel that it is futile and counter-productive to argue that one type of bias is inherently more detrimental than the other, because there is no theoretical reason to compete for title "of the most fatal flaw" in occupational epidemiology. Thus, I will proceed on the assumption that reader will not wish to denigrate on one source of bias over another, but will instead commit to examination of one of the many villains undermining validity of inference in occupational epidemiology: measurement error and misclassification of exposure.

The most dramatic advance in occupational epidemiology recently occurred in the realm of methods to assess exposures, which increased qualitatively in both transparency and sophistication leveraging the ever-increasing knowledge about levels and patterns of occupational exposure (e.g.[18-25]). Although improvements are virtually assured from these advances, some biases may be unanticipated.[26]

The focus of this article is recent five years. Since 2013, by even a modest and crude count, there were tens of thousands of scientific publications in occupational epidemiology,[27] most undoubtedly discussing bias from errors in assessed exposures. The importance of such errors is ingrained in the minds of occupational epidemiologists through textbooks,[28] but they are typically treated in interpretation of epidemiologic studies superficially.[29] To wit, I was able to find only five papers published since 2013 that corrected or adjusted for errors in exposure in the realm of occupational epidemiology[30-33, 11]; all but [11] used Bayesian methods. Almost none of published studies in occupational epidemiology adjusted for measurement error, despite widespread appreciation that it is a non-ignorable threat to valid inference and availability of suitable tools. This is disappointing, given that nutritional epidemiologists mounted a robust methodological response to measurement error problem that features full application of power of modern statistics, with more than 100 publications on development and application of measurement error correction methods in practice [34] and thousands of citations of seminal article on regression calibration that appeared in 1989.[35] Medical and epidemiologic literature overall was reported to contain 7\% of articles that corrected for measurement error in 2016.[36] Thus, although words of Willett from 1989 sadly still rings true, occupational epidemiology is making slower progress than epidemiology in general:

"Procedures to correct estimates of association in epidemiologic studies for the effects of exposure measurement error have rarely been employed in practice.”[37]

I start with review of the most widely-held misconceptions, before offering one vision of the path towards diminishing harm from errors in exposure suffered by occupational epidemiology. Some thoughts are offered on how to overcome reluctance of occupational epidemiologists to embrace bias-correction procedures that are common to related disciplines. (However, it must be admitted that yet another admonition not to ignore measurement error is unlikely to have an impact: such articles have been routinely published over many decades to no effect). I will not review measurement error and misclassification correction methods in any detail, because these are exhaustively covered in numerous statistical monographs. 


\section{Common misconceptions refuted}

\section{Correction for error-in variable is not just guesses}

The following decade-old advice from trusted sources may have discourage progress on quantitatively accounting for errors in exposures:

"Statistical methods to adjust for misclassification ... are, however, often just guesses. For this reason, we do not advocate reporting 'misclassification-adjusted' effect estimates”.[38]

This guidance is not defensible in light of statistical theory and practice that shows that use of even incomplete knowledge of misclassification model leads to more trustworthy inference than naïve analysis.[39, 40] Misclassification-adjusted effects must be reported!

\section{Reliability does not equal validity}

It is a commonplace for occupational epidemiologist to compare two methods of exposure assessment and claim that one is validated (even in the best-conducted comparisons of this type e.g. [41]). This is incorrect, because all estimates in exposure, even those that employ either direct measurements of exposure or their biomarkers, contain error with respect to the unmeasurable biologically effective dose. Two exposure estimates can be in perfect agreement with each other, and yet bear no relation to the truth, for example due to shared error derived from omissions in description of occupational histories. On the bright side, it is possible to draw some insights into validity from assessment of reliability under some assumptions (as shown by White et al.[3]); Burtsyn et al.[42] showed the limit of what we can learn about sensitivity and specificity from $\kappa$ statistic under two independent assessors of equal validity. Nutritional epidemiologists faced the same challenge by developing various methods of modeling latent true exposure from multiple observations, including methods of triads,[43] derived from the related concept of “alloyed gold standard”.[44] Comforting belief that agreement (or consensus) equal validity may have lulled occupational epidemiologists into a false sense of security, demotivating tackling the problem using modern statistical tools.

\section{We cannot predict impact of error in exposure in every analysis}

Theory of error in exposure describes expectation of bias, i.e. what happens over many repetitions of the same analysis, on average, not in every specific case.[45, 46] Expectation of bias is completely useless in making inference from naïve analysis, contrary to often-repeated claims.[17] This is emphatically demonstrated even in an idealized case.[47] When several imperfectly observed exposures are considered, even relative ranking of strengths of associations is impossible to intuit.[4] The claim that non-differential error in exposure excuses correcting for such errors, because their impact is known to only and always attenuate exposure-response is no longer tenable.

\section{We cannot predict consequences of correcting for error in exposure}

Common objection to accounting for measurement error and misclassification is based on a speculation that we can predict the outcome of such a correction: why bother with extra work if the outcome is a foregone conclusion? However, this is not true. The following are some examples of work that undermines intuition. Correction for non-differential misclassification can either weaken or reverse (but not strengthen) the evidence about direction of the unmatched case-control analysis with non-differential exposure misclassification,[48] but can also produce more precise effect estimates that are less biased.[49] On the other hand, the p-values of likelihood ratio test tend to be unchanged after adjustment for non-differential misclassification, even though point estimates tends to increase,[50] stressing that the real value of such analyses is to support risk assessment and standard-setting. Statistical literature on exposure misclassification is full of counter-intuitive findings such as "sometimes uncertainty about the exposure-disease association can be decreased upon admitting that the sensitivity and specificity are not known exactly!’[48, 40] Thus, it would appear that it is more prudent to correct for error in variables 
instead of trying to guess what effect such a correction may have: "there does not seem to be a substitute for actually implementing an adjustment ....”[48]

\section{It is never safe to assume that exposure misclassification is non-differential with respect to the outcome}

Next, I show that even the refuge of non-differential error exposures is no longer available in even the best-conducted epidemiologic studies that blind exposure assessment to outcome. Evidence that nondifferential measurement error is expected to leads to differential exposure misclassification dates back at least to Flegal et al.,[51] with formal general proof given by Gustafson \& Le,[52] and repeated in even a more accessible form by Singer et al.[30] in their Appendix A. This differential misclassification arises when exposure and outcome are related (either causally or due to confounding) and exposure categories are created under incomplete knowledge of true continuous exposure. Confounding is almost impossible to rule out and epidemiologists conduct studies under hypothesis that exposure causes disease. Exposure assessors, even when using measurements and certainly when using professional judgement, do so with some uncertainty. Thus, even if the usual precautions are taken to blind exposure assessment to the outcome, the most consistent belief under which to analyze a study in occupational epidemiology is that differential misclassification due to dichotomization (DDD) cannot be ruled out. Consequently, bias from error in exposure cannot be predicted from heuristics derived from knowledge of the expected impact of non-differential exposure misclassification on regression analysis. Curiously, DDD can induce less bias than comparable non-differential misclassification, such that assumption of differential misclassficication can guard against over-correction[52]: paradoxically, it seems safer to assume differential misclassification. Matters are more complex when exposure assessment procedure produces more than one classification of exposures.[53, 54]

\section{We do not fully understand how common exposure assessment approaches distort} exposure

One of the pre-requisites for adjustment for error in exposure is to have a model of how observed (or assessed exposure) relates to true exposure. Although important advances have been made in understanding measurement error models that arise from commonly employed exposure assessment approaches, such as group-based exposure assessment [55] and some of the job-exposure matrices (JEM), [26] these revealed that archetypal measurement error and misclassification models do not result from them. In group-based exposure assessment, contrary to earlier belief,[56] Berkson-type error is only approximated [57] and therefore bias it creates can only be partially removed using Berkson error model.[58] Even when Berkson error model is a reasonable approximation, its impact and correction for effects is far from worked out for binary outcomes and survival analyses. The matters are even more complex if error is multiplicative rather than additive [59, 60] or is proportional to true exposure.[61] It must also be noted that portability of a JEM is not assured between jurisdictions[62] and genders within one jurisdiction.[63]

Very few exposure assessment algorithms have been a subject of a theoretical study and therefore we do not know how they distort true exposures. This should be a fruitful area of research because modern exposure assessment algorithms are characterized by transparency in how they treat information on levels and determinants of exposure,[64, 19] unlike the historical "black box" expert assessments. Once any exposure assessment algorithm (such as JEM) undergoes such examination, it can be applied in conjunction with adjustment for misclassification.[11]

Even if it is clarified how true and assigned exposures are related at the level of a single job in occupational history, there is currently virtually no understanding how use of wrong dose metrics biases analyses. This form of measurement error was treated as model miss-specification problem in a book by Smith \& Kriebel, [65] but can equally be treated as a measurement error problem, such as when we wish to estimate cumulative exposure, but are only able to calculate its duration. The general issue has been 
framed long ago,[66] but analytical solution remained elusive other than to urge development of theoretically justified dose metrics[65] in conjunction with empirically selecting dose metrics with best predictive power.[67, 68] Viewing of the problem from measurement error perspective offers avenue for progress towards understanding both the potential biases and correction methods.

\section{Shapes of exposure-response curves cannot be inferred in presence of measurement error}

It has become fashionable to use splines and related methods to explore complexities of shapes in exposure-response curves. However, all such methods are vulnerable to measurement error that can both distort and manufacture shapes that are different from the true ones. This is well known in statistics but is slow to be realized in occupational epidemiology, despite some recent effort at knowledge-translation.[54, 69-71] I can only plead that any future efforts to understand shape of exposure-response associations are to be coupled with correction for errors in exposure (at the very least).

\section{False positives are expected to arise from measurement error}

Statistical theory advanced to the point where it is wrong to claim that classical measurement error or exposure misclassification that are non-differential with respect to outcome always mask or dilute true risks, producing only false negative findings. In general, both false positive and negative estimates are possible even under optimistic assumption of non-differential exposure misclassification [72] or random error.[73] The heuristic that explains this is that by adding random noise to any system as input, we can expect to get more noise as output. More formally, error in exposure dilutes power of regression models in a manner that both type 1 and type 2 errors are affected, hence the risk of both false positives and negatives following frequentist hypothesis testing at higher than nominal rates. Mathematically, the only condition under which false positives can be ruled out is to interpret empirical result under a priori assumption that exposure causes outcome,[72] which is an untenable position in most epidemiologic research, unless the aim is to better quantify know association for risk assessment, leaving the question of false positive or negative result moot.

A colleague once challenged me to consider whether measurement error correction procedures can manufacture positive results, a concern that prevents some epidemiologists from embracing the techniques. Theory does not seem to contain such fears and simulations can be readily performed to show that false positives do not arise in Bayesian correction for measurement error.[74] When such concerns exist, they can be studied and are not a barrier to application of error-correction methods, just as more valid exposure data is never a source of a greater bias.

\section{Correction for error in exposure matters for risk assessment!}

Although occupational epidemiologists champion improvements in exposure assessment to help inform policy, the same zeal is yet to translate to realization that correction for measurement error can have a profound effect on risk assessment via the calculation of population-attributable fraction. This happens not only because per-unit-exposure risk estimates change, but also distribution of observed exposure is corrected to its true value, often dramatically.[75, 76] Other subtle matters related to non-ignorable role of measurement error problem in public health policy-making are reviewed by Edwards \& Keil.[77]

\section{Perspective on overcoming the problem}

First, let me motivate correction (adjustment) for exposure measurement error and misclassification in a manner that I find compelling: not to get better qualitative test of whether an association exist (e.g. via some error-corrected hypothesis test) but to obtain less biased effect estimate that is useful in risk assessment. After all, modern occupational epidemiology is less motivated by discovery of associations (e.g. we can all agree that exposure X can be bad; statistically crude tools of epidemiology of mid- $20^{\text {th }}$ century were already adept at this), but by application to risk assessment (e.g. where to set exposure limit for harmful exposure). Prof. Lash recently even advanced an argument that hypothesis-testing tradition 
harms epidemiology.[78] Thus, going forward, I will dismiss considerations of hypothesis tests, a search for "statistically significant" results, as unworthy of future epidemiologists. On the other hand, the following avenues of activities appear to be worth encouraging:

1. Admit that measurement error and exposure misclassification can no longer be talked-away.

2. Gather more measurements of workplace exposures of higher quality: nothing will replace better exposure data in addressing measurement error and misclassification problems. A related activity is to conduct more reliability studies and interpret them in context to what such work tells us about validity. This should enable calibration of costly exposure assessment methods (expert review, biomarkers) with respect to cheaper ones that are applicable in epidemiologic setting.

3. Understand what sort of error-in-exposure models arise in occupational epidemiology and stimulate theoretical developments that customize statistical tools to the needs of occupational epidemiologists.

4. Apply error correction techniques that already have a stellar track record of improving inference in regression analyses in related disciplines, such as nutritional and radiation epidemiology.

\section{On education and career-long incentives}

There is an educational barrier: measurement error and misclassification are not an important part of curriculum of doctoral-level training in (occupational) epidemiology. This is the most easily remedied matter going forward and can be amplified through continuous education and professional development of epidemiologists through suitable incentives. For example, one can imagine conferences, professional societies, or journals awarding prizes for innovative contributions to measurement error and misclassification of exposure in occupational epidemiology. Most helpful though would be for sponsors of research to favor (or solicit) grant applications that tackle error-in-exposure problem using modern methods, coming to such low-cost high-return efforts over long periods of time.

\section{Dismantle culture of the "main” versus "methodological” paper}

I encountered view among epidemiologists that any error correction must support the naive uncorrected analysis. Whatever the cause of this attitude, it hampers advances in the field, because it demotivates, any formal error correction: nobody wants to make an effort that is guided to make no impact on interpretation of an important results. To make any genuine progress towards adoption of modern statistics in modern epidemiology (thus making it modern), the paradigm of "main" vs. "subordinate/methodological" paper must vanish. Instead, irrespective of results, the analysis that makes better use of data and is more theoretically justified must be accepted as superior, even if it contradicts earlier analysis of the same data. These considerations are not unique to correction for error in exposure, but appear to have caused occupational epidemiology to lag behind times in tackling the problem.

\section{Mistrust intuition about mathematics that codifies our biases}

As I demonstrated, it is very hard to foretell, intuitively, how error in exposure will affect analysis and what will result if we correct for such errors analytically. This is echoed by Prof. Greenland:

"Misclassification seems especially tricky to study, given that even simple cases can lead to nonintuitive biases and to formulas more involved than analogous results for confounding and selection bias.”[79]

However, this should not leave us despondent but to encourage both theoretical and numerical investigations into these issues so that "many more interesting and useful results will arise from exploring the limits of past intuitions and heuristics." [79] Simulation studies in particular are readily accessible to all epidemiologists and can be readily deployed in the future to gain better insights into measurement error issues, as they have been in the past. 


\section{Another argument for Bayesian approach}

I cannot hope to be more entertaining and compelling in arguing for admitting that all occupational epidemiologists are Bayesians than Pearce \& Corbin.[80] There is no rebuttal to their philosophy, because there is not a single occupational epidemiologists who operates without a hypothesis of how exposure affects risk and has some pre-existing data on how good their tools are for detecting a believable association: if this were not true, all power and sample size calculations would be fraud (I believe that they are not). Consequently, I will not defend Bayesian statistics here further but will simply highlight how they already helped to make the problem of error in exposure not so in intractable that it can only be "talked-away" in discussion sections of manuscripts. Although we do not know measurement error model in most of occupational epidemiology studies, there may be a Bayesian shortcut to analytically dealing with a multitude of error in exposure problems. No matter how complex an exposure assessment process, it almost always leads to segregation of subjects into exposed and unexposed by some metrics (e.g. exposed to more than $\mathrm{X}$ unit-years 5 to 15 years before censoring/outcome). (The matters are more complex with multiple categories[12, 13] but we need not face this, because vast majority of epidemiologic analyses can be reduced to dichotomization of exposures.) This is precisely the misclassification problem that is governed by sensitivity and specificity and is conceptually not different from human experts or algorithm classifying exposes of subjects via some devilishly complex mental effort. Consequently, we are left with misclassification differential-due-to-dichotomization: a continuous error-prone exposure construct reduced to binary classification.[52] We are certain that such classification is better than chance alone and can refine knowledge of sensitivity and specificity in a variety of ways, e.g. via assessment of reliability[42, 81, 31], by prior elucidation from experts[9], simulations,[54] or insights from previous corrections.[82, 30] (I recommend work of Moyé [83] for conceptual guidance on fair elucidation of prior probabilities.) Armed with such an insight, a path towards calculating impact of error-in-exposure and correction for bias it creates is open. At least this path is worth treading to see whether it often leads us astray, in hope of refining it. Such effort is in the context of occupational epidemiology is exemplified by Singer et al.[30]

\section{Conclusion}

This perspective is guaranteed to be incomplete and biased by my experiences and beliefs, as befits a selfconfessed Bayesian. Yet it may be useful in facilitating the entry of occupational epidemiology into an era when it is commonplace to correct for bias due to errors in exposure, just as it is now commendable to seeking better exposure data. Correction for measurement error and misclassification of exposure is tantamount to seeking more valid exposure data and therefore should be embraced by occupational epidemiologists, as is becoming more common in other epidemiologic applications. It is true that attaining perfect exposure estimate can only be imagined, never realized. Yet the quests for the imaginary truth are the most worthy of our devotion: we need more questing epidemiologists to selflessly pursue taming the problem of errors in exposures by all possible paths.

\section{References}

1. Preller L, Kromhout H, Heederik D, Tielen MJ. Modeling long-term average exposure in occupational exposure-response analysis. ScandJWork EnvironHealth. 1995;12(6):504-12.

2. Armstrong BG. Effect of measurement error on epidemiological studies of environmental and occupational exposures. Occupational and Environmental Medicine. 1998;55(10):651-6.

3. White E, Armstrong BK, Saracci R. Principles of exposure measurement in epidemiology: collecting, evaluating and improving measures of disease risk factor. 2 ed. Oxford University Press; 2008. 
4. Gustafson P. Measurement Error and Misclassification in Statistics and Epidemiology. Chapman \& Hall/CRC Press; 2004.

5. Carroll RJ, Ruppert D, Stefanski LA. Measurement error in nonlinear models. London, England: Chapman and Hall Ltd.; 1995.

6. Carrol RJ, Ruppert D, Stefanski LA, Crainiceanu CM. Measurement error in Nonlinear Models. 2 ed. Monographs on Statistics and Applied Probability 105. Boca Raton, FL, USA: Chapman \& Hall/CRC; 2006.

7. Fuller WA. Measurement error models. New York, USA: John Wiley \& Sons; 1987.

8. Luta G, Ford MB, Bondy M, Shields PG, Stamey JD. Bayesian sensitivity analysis methods to evaluate bias due to misclassification and missing data using informative priors and external validation data. Cancer Epidemiol. 2013;37(2):121-6. doi:10.1016/j.canep.2012.11.006.

9. Liu J, Gustafson P, Cherry N, Burstyn I. Bayesian analysis of a matched case-control study with expert prior information on both the misclassification of exposure and the exposure-disease association. StatMed. 2009;28(27):3411-23.

10. Espino-Hernandez G, Gustafson P, Burstyn I. Bayesian adjustment for measurement error in continuous exposures in an individually matched case-control study. BMC Medical Research Methodology. 2011;11:67:http://www.biomedcentral.com/1471-2288/11/67.

11. Greenland S, Fischer HJ, Kheifets L. Methods to Explore Uncertainty and Bias Introduced by Job Exposure Matrices. Risk Anal. 2016;36(1):74-82. doi:10.1111/risa.12438.

12. Liu Y, Liu J, Zhang F. Bias analysis for misclassification in a multicategorical exposure in a logistic regression model. Statistics \& Probability Letters. 2013;83(12):2621-6.

13. Wang D, Shen T, Gustafson P. Partial Identification arising from Nondifferential Exposure Misclassification: How Informative are Data on the Unlikely, Maybe, and Likely Exposed? The International Journal of Biostatistics. 2012;8(1):1557-4679. doi: https://doi.org/10.1515/1557-4679.1397.

14. Lash TL. Bias analysis applied to Agricultural Health Study publications to estimate non-random sources of uncertainty. J Occup Med Toxicol. 2007;2:15. doi:10.1186/1745-6673-2-15.

15. Maldonado G. Adjusting a relative-risk estimate for study imperfections. J Epidemiol Community Health. 2008;62(7):655-63. doi:10.1136/jech.2007.063909.

16. Lash TL, Fox MP, MacLehose RF, Maldonado G, McCandless LC, Greenland S. Good practices for quantitative bias analysis. Int J Epidemiol. 2014;43(6):1969-85. doi:10.1093/ije/dyu149.

17. Blair A, Stewart P, Lubin JH, Forastiere F. Methodological issues regarding confounding and exposure misclassification in epidemiological studies of occupational exposures. Am J Ind Med. 2007;50(3):199-207. doi:10.1002/ajim.20281.

18. Friesen MC, Shortreed SM, Wheeler DC, Burstyn I, Vermeulen R, Pronk A et al. Using hierarchical cluster models to systematically identify groups of jobs with similar occupational questionnaire response patterns to assist rule-based expert exposure assessment in population-based studies. Ann Occup Hyg. 2015;59(4):455-66. doi:10.1093/annhyg/meu101.

19. Wheeler DC, Burstyn I, Vermeulen R, Yu K, Shortreed SM, Pronk A et al. Inside the black box: starting to uncover the underlying decision rules used in a one-by-one expert assessment of occupational exposure in case-control studies. OccupEnvironMed. 2013;70(3):203-10. doi:oemed-2012-100918

[pii];10.1136/oemed-2012-100918 [doi]. 
20. Lee DG, Lavoue J, Spinelli JJ, Burstyn I. Statistical Modeling of Occupational Exposure to Polycyclic Aromatic Hydrocarbons Using OSHA Data. J Occup Environ Hyg. 2015;12(10):729-42. doi:10.1080/15459624.2015.1043049.

21. Peters S, Vermeulen R, Portengen L, Olsson A, Kendzia B, Vincent R et al. SYN-JEM: A Quantitative Job-Exposure Matrix for Five Lung Carcinogens. Ann Occup Hyg. 2016;60(7):795-811. doi:10.1093/annhyg/mew034.

22. Dopart PJ, Friesen MC. New Opportunities in Exposure Assessment of Occupational Epidemiology: Use of Measurements to Aid Exposure Reconstruction in Population-Based Studies. Curr Environ Health Rep. 2017;4(3):355-63. doi:10.1007/s40572-017-0153-0.

23. Siemiatycki J, Lavoue J. Availability of a New Job-Exposure Matrix (CANJEM) for Epidemiologic and Occupational Medicine Purposes. J Occup Environ Med. 2018;60(7):e324-e8. doi:10.1097/JOM.0000000000001335.

24. Kirkham TL, Siemiatycki J, Labreche F, Lavoue J. Impact of aggregating exposure information from cases and controls when building a population-based job-exposure matrix from past expert evaluations. Occup Environ Med. 2016;73(7):474-81. doi:10.1136/oemed-2014-102690.

25. Ge CB, Friesen MC, Kromhout H, Peters S, Rothman N, Lan Q et al. Use and Reliability of Exposure Assessment Methods in Occupational Case-Control Studies in the General Population: Past, Present, and Future. Ann Work Expo Health. 2018. doi:10.1093/annweh/wxy080.

26. Burstyn I, Lavoue J, Van TM. Aggregation of exposure level and probability into a single metric in job-exposure matrices creates bias. AnnOccupHyg. 2012;56(9):1038-50. doi:mes031 [pii];10.1093/annhyg/mes031 [doi].

27. Stayner LT, Collins JJ, Guo YL, Heederik D, Kogevinas M, Steenland K et al. Challenges and Opportunities for Occupational Epidemiology in the Twenty-first Century. Curr Environ Health Rep. 2017;4(3):319-24. doi:10.1007/s40572-017-0154-z.

28. Checkoway H, Pearce N, Crawford-Brown DJ. Research Methods in Occupational Epidemiology. 1 ed. New York: Oxford University Press, Inc.; 1989.

29. Jurek AM, Maldonado G, Greenland S, Church TR. Exposure-measurement error is frequently ignored when interpreting epidemiologic study results. EurJEpidemiol. 2006;21(12):871-6.

30. Singer AB, Daniele Fallin M, Burstyn I. Bayesian Correction for Exposure Misclassification and Evolution of Evidence in Two Studies of the Association Between Maternal Occupational Exposure to Asthmagens and Risk of Autism Spectrum Disorder. Curr Environ Health Rep. 2018;5(3):338-50. doi:10.1007/s40572-018-0205-0.

31. Burstyn I, Gustafson P, Pintos J, Lavoue J, Siemiatycki J. Correction of odds ratios in case-control studies for exposure misclassification with partial knowledge of the degree of agreement among experts who assessed exposures. Occup Environ Med. 2018;75(2):155-9. doi:10.1136/oemed-2017-104609.

32. Bartell SM, Hamra GB, Steenland K. Bayesian Analysis of Silica Exposure and Lung Cancer Using Human and Animal Studies. Epidemiology. 2017;28(2):281-7. doi:10.1097/EDE.0000000000000602.

33. Hoffmann S, Rage E, Laurier D, Laroche P, Guihenneuc C, Ancelet S. Accounting for Berkson and Classical Measurement Error in Radon Exposure Using a Bayesian Structural Approach in the Analysis of Lung Cancer Mortality in the French Cohort of Uranium Miners. Radiat Res. 2017;187(2):196-209. doi:10.1667/RR14467.1.

34. Bennett DA, Landry D, Little J, Minelli C. Systematic review of statistical approaches to quantify, or correct for, measurement error in a continuous exposure in nutritional epidemiology. BMC Med Res Methodol. 2017;17(1):146. doi:10.1186/s12874-017-0421-6. 
35. Rosner B, Willett WC, Spiegelman D. Correction of logistic regression relative risk estimates and confidence intervals for systematic within-person measurement error. StatMed. 1989;8(9):1051-69.

36. Brakenhoff TB, Mitroiu M, Keogh RH, Moons KGM, Groenwold RHH, van Smeden M. Measurement error is often neglected in medical literature: a systematic review. J Clin Epidemiol. 2018;98:89-97. doi:10.1016/j.jclinepi.2018.02.023.

37. Willett W. An overview of issues related to the correction of non-differential exposure measurement error in epidemiologic studies. Stat Med. 1989;8(9):1031-40; discussion 71-3.

38. Pearce N, Checkoway H, Kriebel D. Bias in occupational epidemiology studies. OccupEnvironMed. 2007;64(8):562-8.

39. Gustafson P. Bayesian inference for partially identified models. IntJ Biostat. 2010;6(2):Article.

40. Gustafson P, Le ND, Saskin R. Case-control analysis with partial knowledge of exposure misclassification probabilities. Biometrics. 2001;57(2):598-609.

41. Friesen MC, Coble JB, Katki HA, Ji BT, Xue S, Lu W et al. Validity and reliability of exposure assessors' ratings of exposure intensity by type of occupational questionnaire and type of rater. Ann Occup Hyg. 2011;55(6):601-11. doi:10.1093/annhyg/mer019.

42. Burstyn I, de VF, Gustafson P. What do measures of agreement (kappa) tell us about quality of exposure assessment? Theoretical analysis and numerical simulation. BMJ Open. 2013;3(12):e003952. doi:bmjopen-2013-003952 [pii];10.1136/bmjopen-2013-003952 [doi].

43. Kaaks R, Ferrari P. Dietary intake assessments in epidemiology: can we know what we are measuring? Ann Epidemiol. 2006;16(5):377-80. doi:10.1016/j.annepidem.2005.06.057.

44. Spiegelman D, Schneeweiss S, McDermott A. Measurement error correction for logistic regression models with an "alloyed gold standard". AmJ Epidemiol. 1997;145(2):184-96.

45. Jurek AM, Greenland S, Maldonado G, Church TR. Proper interpretation of non-differential misclassification effects: expectations vs observations. IntJEpidemiol. 2005;34(3):680-7.

46. Sorahan T, Gilthorpe MS. Non-differential misclassification of exposure always leads to an underestimate of risk: an incorrect conclusion. Occup Environ Med. 1994;51(12):839-40.

47. Brakenhoff TB, van Smeden M, Visseren FLJ, Groenwold RHH. Random measurement error: Why worry? An example of cardiovascular risk factors. PLoS One. 2018;13(2):e0192298.

doi:10.1371/journal.pone.0192298.

48. Gustafson P, Greenland S. Curious phenomena in Bayesian adjustment for exposure misclassification. StatMed. 2006;25(1):87-103.

49. Wang M, Liao X, Spiegelman D. Can efficiency be gained by correcting for misclassification? J Stat Plan Inference. 2013;143(11). doi:10.1016/j.jspi.2013.06.010.

50. Greenland S, Gustafson P. Accounting for independent nondifferential misclassification does not increase certainty that an observed association is in the correct direction. AmJEpidemiol. 2006;164(1):638.

51. Flegal KM, Keyl PM, Nieto FJ. Differential misclassification arising from nondifferential errors in exposure measurement. AmJ Epidemiol. 1991;134(10):1233-44.

52. Gustafson P, Le Nhu D. Comparing the effects of continuous and discrete covariate mismeasurement, with emphasis on the dichotomization of mismeasured predictors. Biometrics. 2002;58(4):878-87.

53. Richardson DB, Loomis D. The impact of exposure categorisation for grouped analyses of cohort data. Occup EnvironMed. 2004;61(11):930-5. 
54. Heavner K, Burstyn I. A Simulation Study of Categorizing Continuous Exposure Variables Measured with Error in Autism Research: Small Changes with Large Effects. Int J Environ Res Public Health. 2015;12(8):10198-234. doi:10.3390/ijerph120810198.

55. Kim HM, Richardson D, Loomis D, vanTongeren M, Burstyn I. Bias in the estimation of exposure effects with individual- or group-based exposure assessment. JExpoSciEnvironEpidemiol. 2011;21(2):212-21. doi:jes200974 [pii];10.1038/jes.2009.74 [doi].

56. Tielemans E, Kupper LL, Kromhout H, Heederik D, Houba R. Individual-based and group-based occupational exposure assessment: Some equations to evaluate different strategies. AnnOccupHyg. 1998;42(2):115-9.

57. Kim HM, Yasui Y, Burstyn I. Attenuation in risk estimates in logistic and Cox proportional-hazards models due to group-based exposure assessment strategy. AnnOccupHyg. 2006;50(6):623-35.

58. Kim H-M, Burstyn I. Bayesian method for improving logistic regression estimate under group-based exposure assessment with additive measurement error. Archives of Environmental and Occupational Health. 2009;64(4):261-5.

59. Heid IM, Kuchenhoff H, Wellmann J, Gerken M, Kreienbrock L, Wichmann HE. On the potential of measurement error to induce differential bias on odds ratio estimates: an example from radon epidemiology. StatMed. 2002;21(21):3261-78.

60. Reeves GK, Cox DR, Darby SC, Whitley E. Some aspects of measurement error in explanatory variables for continuous and binary regression models. StatMed. 1998;17(19):2157-77.

61. Burstyn I, Kim HM, Cherry N, Yasui Y. Metamodels of bias in Cox proportional-hazards and logistic regressions with heteroscedastic measurement error under group-level exposure assessment. AnnOccupHyg. 2006;50(3):271-9.

62. Lavoue J, Pintos J, Van TM, Kincl L, Richardson L, Kauppinen T et al. Comparison of exposure estimates in the Finnish job-exposure matrix FINJEM with a JEM derived from expert assessments performed in Montreal. OccupEnvironMed. 2012;69(7):465-71. doi:oemed-2011-100154 [pii];10.1136/oemed-2011-100154 [doi].

63. Kennedy SM, Koehoorn M. Exposure assessment in epidemiology: does gender matter? Am J Ind Med. 2003;44(6):576-83. doi:10.1002/ajim.10297.

64. Burstyn I, Boffetta P, Kauppinen T, Heikkila P, Svane O, Partanen T et al. Estimating exposures in the asphalt industry for an international epidemiological cohort study of cancer risk. American Journal of Industrial Medicine. 2003;43(1):3-17.

65. Smith TJ, Kriebel D. A Biologic Approach to Environmental Assessment and Epidemiology New York, NY, USA: Oxford University Press; 2010.

66. Johnson ES. Duration of exposure as a surrogate for dose in the examination of dose response relations. Br J Ind Med. 1986;43(6):427-9.

67. Seixas NS, Robins TG, Becker M. A novel approach to the characterization of cumulative exposure for the study of chronic occupational disease. American Journal of Epidemiology. 1993;137(4):463-71.

68. Kriebel D, Checkoway H, Pearce N. Exposure and dose modelling in occupational epidemiology. Occup Environ Med. 2007;64(7):492-8. doi:10.1136/oem.2006.030031.

69. Crump KS. The effect of random error in exposure measurement upon the shape of the exposure response. Dose Response. 2006;3(4):456-64. doi:10.2203/dose-response.003.04.002. 
70. Rhomberg LR, Chandalia JK, Long CM, Goodman JE. Measurement error in environmental epidemiology and the shape of exposure-response curves. Crit Rev Toxicol. 2011;41(8):651-71. doi:10.3109/10408444.2011.563420.

71. Hoffmann S, Laurier D, Rage E, Guihenneuc C, Ancelet S. Shared and unshared exposure measurement error in occupational cohort studies and their effects on statistical inference in proportional hazards models. PLoS One. 2018;13(2):e0190792. doi:10.1371/journal.pone.0190792.

72. Burstyn I, Yang Y, Schnatter AR. Effects of non-differential exposure misclassification on false conclusions in hypothesis-generating studies. IntJ EnvironResPublic Health. 2014;11(10):10951-66. doi:ijerph111010951 [pii];10.3390/ijerph111010951 [doi].

73. Loken E, Gelman A. Measurement error and the replication crisis. Science 2017;355(6325):584-5. doi:10.1126/science.aal3618.

74. Burstyn I. Does adjustment for measurement error induce positive bias if there is no true association? arXiv. 2009;0902.1193v1 [stat.AP].

75. Burstyn I, Kapur N, Cherry NM. Substance use of pregnant women and early neonatal morbidity: where to focus intervention? CanJPublic Health. 2010;101(2):149-53.

76. Wong BHW, Peskoe SB, Spiegelman D. The effect of risk factor misclassification on the partial population attributable risk. Stat Med. 2018;37(8):1259-75. doi:10.1002/sim.7559.

77. Edwards JK, Keil AP. Measurement Error and Environmental Epidemiology: a Policy Perspective. Curr Environ Health Rep. 2017;4(1):79-88. doi:10.1007/s40572-017-0125-4.

78. Lash TL. The Harm Done to Reproducibility by the Culture of Null Hypothesis Significance Testing. Am J Epidemiol. 2017;186(6):627-35. doi:10.1093/aje/kwx261.

79. Greenland S. Intuitions, simulations, theorems: the role and limits of methodology. Epidemiology. 2012;23(3):440-2. doi:10.1097/EDE.0b013e31824e278d.

80. Pearce N, Corbin M. Why should we be Bayesians (and often already are without realizing it). In: Venables.K.M., editor. Current topics in occupational epidemiology. Oxford, England: Oxford University Press; 2013. p. 218-33.

81. Goldstein ND, Welles SL, Burstyn I. To Be or Not to Be: Bayesian Correction for Misclassification of Self-reported Sexual Behaviors Among Men Who Have Sex with Men. Epidemiology. 2015;26(5):63744. doi:10.1097/EDE.0000000000000328 [doi].

82. Beach J, Burstyn I, Cherry N. Estimating the extent and distribution of new-onset adult asthma in British Columbia using frequentist and Bayesian approaches. AnnOccupHyg. 2012;56(6):719-27. doi:mes004 [pii];10.1093/annhyg/mes004 [doi].

83. Moye LA. Developing prior probability. Elementray bayesian biostatistics. Boca Raton, FL, USA: Chapman \& Hall/CRC; 2008. p. 163-88. 